\title{
The School of Life Dropout Prevention Curriculum: A Case Report
}

\author{
Grace Wayman \\ Department of Special Education, University of Utah \\ 1705 E. Campus Center Dr. Rm 2246, Salt Lake City, UT 84105, USA
}

Leanne S. Hawken (Corresponding author)

Department of Special Education, University of Utah

1705 E. Campus Center Dr. Rm 2246, Salt Lake City, UT 84105, USA

Tel: 1-801-581-5968Ｅ-mail: leanne.hawken@utah.edu

Hannah M. Wright

Department of Special Education, University of Utah

1705 E. Campus Center Dr. Rm 2246, Salt Lake City, UT 84105, USA

Christian V. Sabey

Department of Special Education, University of Utah

1705 E. Campus Center Dr. Rm 2246, Salt Lake City, UT 84105, USA

Julia Fleming

Department of Special Education, University of Utah

1705 E. Campus Center Dr. Rm 2246, Salt Lake City, UT 84105, USA

Kathleen O’Donnell

Department of Special Education, University of Utah

1705 E. Campus Center Dr. Rm 2246, Salt Lake City, UT 84105, USA 
Jack Rolfe

Department of Special Education, University of Utah

1705 E. Campus Center Dr. Rm 2246, Salt Lake City, UT 84105, USA

Received: July 30, 2019 Accepted: November 29, 2020 Published: January 4, 2021

doi:10.5296/jei.v7i1.15179 URL: https://doi.org/10.5296/jei.v7i1.15179

\begin{abstract}
Students in high school or secondary school face challenges that too often lead them to drop out of school. Administrators and staff in many of these schools have attempted to address this challenge by adopting a framework of Positive Behavior Interventions and Supports (PBIS) that offers graduated tiers of intervention suited to students' needs. One such intervention that has been used in some parts of the US, was developed by the School of Life Foundation (SOLF). The intervention consists of a life-skills curriculum that supports students by addressing factors related to increased probability of dropping out of school. This article provides a case report, from the United States, of the SOLF intervention in the context of a PBIS framework.
\end{abstract}

Keywords: Positive Behavioral Interventions and Supports, School of Life Foundation, Tier 2 intervention, Dropout

\title{
1. Introduction
}

Angel is three months into the senior year of her school career at Meadow Lark High School in the US. Several of her teachers have noticed that she consistently appears to be withdrawn and disinterested in engaging with her peers while she is in class. Furthermore, school data indicate that she has a low rate of work completion, has perpetual tardiness and high rates of absenteeism. Her grades have dropped to the point that she is failing several of her classes. The teachers are concerned that if Angel continues down the current path that she is on, she may not graduate, and may decide to drop out of school. Meadow Lark High School chose to adopt a Positive Behavioral Interventions and Supports (PBIS) framework three years ago, and has scored above $80 \%$ each year on the PBIS implementation fidelity tools, thus indicating that the school has strong school-wide supports in place. The concerns that have been brought up by the teachers are shared with the school-wide problem solving team and the team meets to decide next steps for Angel.

Scenarios similar to the one presented above occur frequently in high schools in the US, and often create challenges to staff and administration that leave them feeling inadequate to provide appropriate supports. Students such as the one described begin to get off-track to graduate and the school must find effective interventions to improve outcomes for these students. It is common for schools across the country to face challenges related to school climate and student 
discipline that have the potential to impact social and academic outcomes for students, as well as lead to the student's decision to dropout of school (Bohanon $\& \mathrm{Wu}, 2014$ ). According to Morrissey, Bohanon and Fenning (2010), students who are unable to meet the continually changing demands of schools, and who are the recipients of traditional reactive approaches to discipline, are more likely to dropout or face punitive measures that do not ultimately improve behaviors. During the 1980s and 1990s, there was a call for educational reform regarding high school dropouts, which resulted in a declining trend in U.S high school dropout rates (Freeman et al., 2015). Although dropout is on the decline, there are many repercussions for students, their communities, and families that are associated with students' choosing to dropout of high school. The overall dropout rate is 6.2 percent in the U.S. and is showing a declining trend (U.S. Department of Education, 2018). However, the impact of students who drop out of high school can be detrimental and is associated with negative employment and life outcomes including needing government assistance, living in poverty, and ending up in prison (Christle, Jolivette, $\&$ Nelson, 2007). Based on these issues, it is imperative that schools find effective, preventative approaches that decrease dropout rates and improve student outcomes post high school.

\section{Dropout Interventions}

Dropout prevention studies lack the rigor or strong evidence to support their overall effectiveness for dropout prevention (Freeman et al., 2015), although various interventions have indicated improvement in outcomes for students graduating high school. Some of the commonly studied interventions (Reconnecting Youth, Check and Connect, PREPaRE) aim to increase skills for students who are at risk for dropping out and show promising results (Alvarez \& Anderson-Ketchmark, 2010; Cheney et al., 2010; Cho, Hallfors, \& Sanchez, 2005; Maynard, Kjellstrand, \& Thompson, 2014; McDaniel, Houchins, \& Robinson, 2016; Sinclair, Christenson, Evelo, \& Hurley, 1998). Reconnecting Youth focused on the effects of a peer group intervention which indicated improved graduation rates along with other positive outcomes (Cho, Hallfors, \& Sanchez, 2005). Check and Connect, which is targeted towards students at-risk for dropping out due to disengagement with school demonstrates effectiveness (Alvarez \& Anderson-Ketchmark, 2010; Cheney et al., 2010; Maynard, Kjellstrand, \& Thompson, 2014; McDaniel, Houchins, \& Robinson, 2016; Sinclair, Christenson, Evelo, \& Hurley, 1998). PREPaRE, which targets interpersonal skills training, indicates that students who were taught proper interactions with peers and others in the community, as well as pertinent social skills, had increased rates of future success and high school graduation.

\section{Positive Behavioral Interventions and Supports}

Much of the recent research focused on supporting students both behaviorally and academically has focused on the use of Positive Behavior Intervention and Support (PBIS) (Bohanon, Flannery, Malloy, \& Fenning, 2009). This multi-tiered approach targets both group and individual needs through a three-tiered prevention model. The three tiers of intensity are intended to match the needs of the students within the school providing a continuum of supports (Bradshaw, Mitchell, \& Leaf, 2010). Tier 1 is designed to support the behavioral needs of most students $(80 \%-90 \%)$ and is a tier that is provided to all students. Tier 2 
interventions are a layer of support that are provided along with Tier 1 supports. Tier 2 interventions target students who need more intensified interventions, typically $10 \%-13 \%$ of the student population. Often, this may include a point system or contract in which several students' behaviors are tracked and the desired behaviors are positively reinforced. Tier 3 interventions are provided to students with more persistent behavioral challenges, and are more intensive and individualized. Tertiary interventions are implemented with approximately $1 \%-5 \%$ of the student population (Swain-Bradway, Pinkney, \& Flannery 2015). Tier 3 behavioral support may be an individualized behavior plan in which staff have identified the function of the behavior and identified a target behavior to replace the problem behavior.

Some schools have begun to implement the use of a PBIS framework to support students and have seen positive outcomes, however most of the research that has been conducted has focused on elementary and middle school level implementation. According to the research, positive outcomes are evident in the areas of academics, (Bradshaw, Mitchell, \& Leaf, 2010; Freeman et al., 2016) elementary, (McIntosh, Bennett, \& Price, 2011), behavior, (Flannery, Frank, Kato, Doren, \& Fenning 2013; Freeman et al., 2016; Vincent \& Tobin, 2011), ethnic groups (Bohanon et al., 2006; Morrissey, Bohanon, \& Fenning, 2010), and social skills (Cheney et al., 2010; McIntosh, Bennett, \& Price, 2011; Ross \& Sabey, 2015). The current research indicates that PBIS implementation in high schools has potential for similar outcomes.

\section{Dropout Prevention in the Context of PBIS}

Although the potential solution to dropout prevention could exist within a well-structured PBIS framework, there are limitations to the current research in the area of high school dropout prevention in the context of PBIS. The research that has been conducted in the area of PBIS implementation in high schools has lacked control groups and experimental research designs that show a positive correlation between PBIS implementation and positive outcomes for high school students (Bradshaw, Mitchell, \& Leaf, 2010; Kato \& McIntosh, 2014). More outcome data in the area of PBIS implementation, including providing Tier 2 and Tier 3 interventions to high school students, is needed at this time.

The school-wide problem solving team at Meadow Lark High School has spent time looking at various interventions that have been provided to students like Angel who have displayed similar at-risk factors for dropping out of high school. They have decided to have Angel join an intervention called School of Life Foundation that the school adopted at the beginning of the school year as a Tier 2 intervention for supporting at-risk students. The intervention has had positive effects on many students in the school and has gained a positive reputation with the student body. Angel is told about the program and agrees to participate starting the following week. The staff is hopeful that it will provide her with the supports that she needs.

\section{School of Life}

The School of Life Foundation (SOLF) intervention is a dropout prevention curriculum based on the "Learn to School Your Toughest Opponent" book, written by Rolfe (2012). It has been implemented in 30 schools across 2 states in the Mountain West region of the US. To date approximately 3,000 students have completed the curriculum. The intervention is provided to 
students who are deemed to be at-risk based on several risk factors including: absenteeism/tardiness, low academics, lacking credits or off-track to graduate, and behavioral issues. Students are selected to participate for four weeks in two-hour sessions which focus on teaching basic social and life skills. The intervention is targeted around 9 A's that provide a framework for the lessons and assignments that students are expected to complete. The A's include: 1) Appreciate, 2) Assist, 3) Attitude, 4) Aim, 5) Align, 6) Action, 7) Associate, 8) Avoid, and 9) Adapt. Within the framework of the A's are two important constructs linked to dropping out: school connectedness and student motivation. Based on SOLF program evaluation data, students who have participated in this intervention in the past three years have seen positive results, including higher rates of graduation (Baggaley, 2015).

The purpose of this article is to provide an overview of the SOLF intervention and summarize its impact on students dropping out. It will also include a description of the lessons provided, their connection to the 9 A's and how the A's connect to the drop-out intervention research. The article will also provide recommendations for best practice implementation.

\subsection{Student Selection Process}

Each school's administrative team defines "at-risk" for their school. Once the risk is determined, students are selected who fit this definition. The most common risk factors are: number of absences/tardies, office discipline referrals, achievement scores and grades. These schools have also identified and trained the staff in implementation of Tier 1 supports in both academics and behavior, therefore when students are brought to a problem solving team the schools can first look at the Tier 1 supports that are in place to see if they are sufficient, or require some additional Tier 2 interventions. Due to the limited resources and costs associated with providing additional interventions, it is pertinent that schools have created a framework and process for identifying a few students who may need the supplemental supports. SOLF is considered a Tier 2 intervention, and thus students identified to have access to the intervention should be appropriately identified by administrative teams prior to participating in the 4-week session.

Once students have been identified they are asked to complete the SOLF Opening Survey and sign an agreement that they are committed to participate in the intervention. This includes participation in all of the sessions, completion of homework and the final project. Schools may choose to provide students with graduation credits or other rewards to in an attempt to increase motivation for completing and engaging in the intervention.

\subsection{The Trainers}

The students who were selected for the SOLF intervention attend weekly two hour sessions after school over a 4-week period of time. During this time student are taught lessons that focus on teaching basic social and life skills that connect with pertinent research regarding dropout factors for students. The individual sessions are delivered by two trainers, one male and one female, who have received 14 hours of training and coaching on how to implement the intervention. Prior to the intervention the trainers undergo extensive training, including a live SOLF class lasting 8 hours, along with an additional 6 hours of a detailed run through of the 
intervention. They are taught best practices in teaching the material, how to manage time and expectations through a scripted delivery of the content. The trainers are either teachers from the school or community members that have expressed the desire to teach the SOLF intervention.

\subsection{Lessons}

Trainers deliver an extensively scripted lesson that gives them prompts regarding the facilitated discussions, and the lesson is delivered through Powerpoint, videos and didactic instruction. Students are both encouraged and expected to participate by answering questions and engaging in the discussions. To get maximum benefit from the intervention, students are asked to answer questions, share stories and ideas, and to engage with the trainers and other student participants. At the end of each session they are also assigned a short homework assignment to provide generalization and practice regarding the content covered. The first three sessions provide instruction, discussion, videos and quotes to exemplify the concepts that are being taught to the students in the framework of the 9 A's.

Each session is structured and follows the same framework: check in, new material, and homework review. The beginning of each lesson starts with reminders and a discussion about homework from the previous session. This is meant to hold students accountable and tie in life experiences with the A's to the session. Students are asked to share and encourage each other as they learn to apply the concepts from SOLF. The next part of the session covers content that targets the selected A's for that week. Students follow along with a workbook as the trainers show videos, share insights, and encourage discussions. The students are shown their homework assignments for that week that they will fill out in the workbook. The conclusion of each session reiterates the content that was covered during that two-hour timeframe, and ends with closing comments and encouragement. Students are reminded about their homework assignments and are left with final thoughts from the trainers through a phone texting application that allows for communication with the students.

The final session of the SOLF intervention is intended to be the climax of the intervention in which students are asked to present the A that impacted them the most and to present in the form of a slide show, musical performance, art, poetry, speech or original video. Regardless of the presentation format and style, each student also hands in a one-page overview that describes and summarizes the project's key points. The trainers stand up with the students after they present and give comments and positive feedback about the students and their participation in the SOLF intervention. Students then celebrate the end of the course by signing certificates. Following the signing of the certificates students complete a closing survey, similar to the one prior to the intervention.

\section{Follow Up}

An important aspect of the SOLF intervention is to provide follow up to students after they have completed the four sessions. Many schools have trainers who are also members of the community or teachers within the school. When students are able to see those adults with whom they have developed a mentoring relationship with, it is a reminder that their success is valued by others and that they need to continue applying the concepts that were learned during 
the intervention. Schools should make a concerted effort to provide opportunities for students who graduated from SOLF intervention to connect with those adults as well as mentor other students who are at-risk and are volunteering to join the intervention. Alumni of the program, who have not yet graduated, can also serve as mentors for recent SOLF graduates. This will essentially build a support system for those students, which they often lack in their own homes or communities away from school. Furthermore, it will provide an opportunity for students to continue applying and generalizing concepts into the different school settings and into their daily lives. School connectedness is a desired outcome for students at-risk, thus the follow-up is an important key to building connection for students.

\section{Connection and the A's}

One important factor related to students choosing to dropout is school connectedness (Niehaus, Rudasill, \& Rakes, 2012). This pertains to a student's belief that the adults in the school care about their learning and about them as individuals (Biag, 2016). When students perceive their school as a place in which they feel a strong connection, it has strong implications for educational success. They often achieve higher grades, have stronger classroom motivation, and higher levels of engagement in school (Niehaus, Rudasill, \& Rakes, 2012). Three of the A's that link to the concept of school connectedness include Assist, Associate and Avoid. These A's are covered across a three-week period of time and are taught through the scripted lessons and homework assignments. For Assist, students are taught the importance of helping others, and they are asked to provide an act of service to someone else over the course of the week for their homework. This assignment provides the opportunity for students to reach out to others in their school and community, which increases the chances of them feeling connected to others. They are also taught important lessons regarding Associate and Avoid. These two A's teach the importance of choosing friends that are positive and in alignment with their life goals. Students are also taught the impact of connection and making friends. They are asked to meet and get to know someone new over the course of the week. For Avoid, students are taught to avoid people, places, and things that are not helping them reach their long and short-term goals. They are also asked to reflect on their current friends and whether those friends are supporting their life and goals. For homework they are asked to identify factors in their lives that should be avoided in order to accomplish their goals.

When students have higher levels of bonding to their school, they are less likely to be retained or drop out of high school (Catalano, Oesterle, Fleming, \& Hawkins, 2004). SOLF targets school connectedness which as research indicates can influence dropout. The more connected students feel, the more likely they are to stay in school and graduate.

\section{Student Motivation and the A's}

Students who choose to dropout of high school often lack motivation and this is a factor that can be targeted through an intervention (Henry, Knight, \& Thornberry, 2012). Some of the characteristics that are included in the realm of motivation include attainment skills, choice-making, decision making, problem solving, self-management, goal-setting, self-efficacy, and self-knowledge (Wehmeyer \& Schwartz, 1997; Zhang \& Law, 2005). SOLF targets many of these characteristics through the A's of Attitude, Aim, Align and Action. 
Students are first taught the importance of having a positive attitude to shape daily experiences and interactions, and are provided homework in which they look in the mirror daily and determine their attitude for the day. They are also encouraged to create mantras or key words that remind them to stick with that particular attitude. This teaches the students self-awareness and sets them up to target the next A taught which is Aim. For Aim, students are taught the skills needed in order to set goals both for long and short-term success. They are taught the acronym SMART (i.e., specific, measurable, appropriate, realistic, and timeline) to support them in effectively writing goals. For their homework assignment they must write both short and long-term goals. The area of Align is addressed in a lesson that teaches students different aspects of creating organizational system that work to support organizing simple spaces in their lives, such as a locker or a closet. The system chosen also helps support students' organization of school work. They must choose an organizational system that will help them in organizing a simple space in their life for homework that week. Lastly, students are taught Action, which connects the actions that they must take to achieve goals in their lives instead of choosing to procrastinate (e.g., making up missed assignments, completing written homework etc.).

These four A's target student motivation and provide a framework for students in which they learn skills in one setting and then are able to generalize the learned concept into another setting through homework and other assignments. This framework has similarities to the self-determination theory (SDT), which focuses on an individual being the locus of causality of his or her behavior (Deci \& Ryan, 2000; Vallerand, Fortier, \& Guay, 1997). The ultimate goal of the SOLF intervention is that students will increase self-motivation by learning to set goals, have self-knowledge and by learning how to attain those goals with the right attitude.

\section{Student Characteristics and the A's}

The SOLF intervention was created to target essential skills for students regarding self-advocacy, motivation and school connectedness. In addition to these components, the intervention also targets the A's Adapt and Appreciate. These two components are important for students' success in the school environment as well as daily life. These other characteristics target student-focused variables that are meant to increase productivity and happiness for the students in their lives.

According to a meta-analysis conducted by Dickens (2017), interventions involving gratitude, or appreciation, can produce positive benefits for people in terms of their well-being and levels of happiness. Therefore, this component of the SOLF intervention seeks to teach students how to be grateful for their friends, family and other aspects of their daily life. The homework for this session involves having students write a thank you letter to someone special in their lives. They are asked to send the letter, or to read it aloud to the person with whom they are thankful, or the students can give a verbal "thank you" to someone whom they believe deserves hearing it. Upon completion of this homework task, in the next session Trainers discuss with students the links between showing appreciation and levels of happiness, and how to build a habit of this practice into their lives.

The other characteristic that is within the realm of a student-focused variable is Adapt. This A teaches students about the importance of being flexible. They are taught about commitment, 
challenge and change, which means when working to achieve goals the students must commit and be ready to face the changes that occur in their lives with openness and flexibility. They are also asked to consider how they may have to change course, if needed, in order to obtain goals. This A aligns well with Aim because it sets students up for success in achieving the goals that they have set out to obtain.

\section{SOLF Embedded Within PBIS}

An important implementation factor for SOLF includes embedding Tier 1, school wide expectations into the lessons and structure of the weekly sessions. Schools have approached this individually because each school has its own Tier 1 expectations, however the selected expectations can then be categorized to fit within the SOLF framework under the A's. The steps needed to embed SOLF intervention within the Tier 1 supports include having administrators give their school wide expectations to the trainers ahead of time so that the trainers can provide positive reinforcement to students when they are engaging in the expectations during the sessions. Additionally, the trainers can also remind students of how the concepts taught in the lessons tie to the school wide expectations. This is an important aspect of the SOLF intervention because it reminds students of the connection of SOLF to their own school's framework for PBIS. It also ensures that SOLF is a Tier 2 intervention that is layered on the Tier 1 supports that are currently in place for students.

\section{Preliminary Data}

Recent quasi-experimental research indicates that the effects of the SOLF have been positive in several areas and shows promising outcomes for students in the area of high school dropout. A recent study (Hawken et al., 2018), analyzed the effects of SOLF on grade advancement/graduation and attendance/tardies. It also looked at the effects on student perceptions of different variables conducted through an Opening and Closing Survey. Prior to the intervention, almost half of the students included in the study were rated as off-track to graduate or to advance a grade by their school administration. Following implementation of SOLF, $85.5 \%$ of those rated off track went on to advance a grade or graduate from high school. Furthermore, there was a statistically significant decrease in the number of days absent prior to the intervention as compared to after the intervention. Students also showed a statistically significant increase in connectedness and student motivation following participation in the intervention as measured by a self-report questionnaire. The extent to which the statistically significant findings represent clinically or practically significant is a matter to be addressed in future research.

The school problem solving team gathers at the end of the quarter (four of the weeks Angel was involved with SOLF) to discuss and review the effects of the SOLF intervention on academics, absences/tardies and motivation for Angel. They analyze her test scores, number of absences/tardies and are pleased to find her grades have increased and if she continues to improve on the same trajectory, she will be on track to graduate. The teachers note anecdotally that Angel appears to be more engaged in class, is turning in assignments on time and is much more engaged in the lessons. Her interactions with peers and with the teachers has increased and she has much more "positive attitude" according to her teachers. The team is pleased with 
the SOLF intervention and will continue to utilize this Tier 2 support for other students with similar needs as Angel.

\section{Summary}

As schools strive to implement effective Tier 2 interventions for students who are at-risk to dropout of high school, it is important to consider those interventions that align with school-wide PBIS, that are evidenced-based, and provide effective outcomes for students. The SOLF intervention is a low-cost, time-efficient option for schools to consider. Due to the nature of this intervention and its links to key variables related to dropout, students have access to information and tools that can support them both in school and also their daily life environments. Furthermore, it provides an opportunity for students to connect with adult mentors and role models who are based both in their schools and in the community. The follow-up that can happen for these students is valuable and a reminder to continue applying the concepts that were learned during their time with SOLF.

School of Life Foundation intervention can be easily tailored to support Tier 1 implementation as detailed in this article. It can provide supplemental, Tier 2 supports to students that is layered on top of the universal supports that the school already has in place. It is an effective intervention for supporting the current issue of high school dropouts and is a tool in the fight to get students back on track to graduate plus provides students with skills that can be utilized throughout their adult lives.

\section{References}

Alvarez, M. E., \& Anderson-Ketchmark, C. (2010). Review of an evidence-based school social work intervention: Check \& connect. Children \& Schools, 32(2), 125-127. https://doi.org/ $10.1093 / \mathrm{cs} / 32.2 .125$

Baggaley, J. (2015). School of life statistical report. Washington County School District Report.

Bergeron, J. L., Nolam, R. F., Dai, Y., \& White, B. (2013). Interpersonal skills training with at-risk high school students. National Forum of Applied Educational Research, 26(3).

Biag, M. (2016). A descriptive analysis of school connectedness: The views of school personnel. Urban Education, 51(1), 32-59. https://doi.org/10.1177/0042085914539772

Bohanon, H., \& Wu, M. (2014). Developing buy-in for positive behavior support in secondary settings. Preventing School Failure, 58(4), 223-229. https://doi.org/10.1080/1045988x. 2013.798774

Bohanon, H., Fenning, P., Carney, K. L., Minnis-Kim, M. J., Anderson-Harriss, S., Mortoz, K. B., ... Pigott, T. D. (2006). Schoolwide application of positive behavior support in an urban high school: A case study. Journal of Positive Behavior Interventions, 8(3), 131-145. https://doi.org/10.1177/10983007060080030201

Bohanon, H., Flannery, B., Malloy, J., \& Fenning, P. (2009). Utilizing positive behavior supports in high school settings to improve school completion rates for students with high 
incidence conditions. Exceptionality, 17, 30-44. https://doi.org/10.1080/09362830802590193

Bradshaw, C. P., Mitchell, M. M., \& Leaf, P. J. (2010). Examining the effects of schoolwide behavioral interventions and supports on student outcomes: Results from a randomized controlled effectiveness trial in elementary schools. Journal of Positive Behavior Interventions, 12, 133. https://doi.org/10.1177/1098300709334798

Catalano, R. F., Oesterle, S., Flemming, C. B., \& Hawkins, J. D. (2004). The importance of bonding to school for healthy development: Findings from the Social Development Research Group. Journal of School Health, 74, 252-261. https://doi.org/10.1111/j.1746-1561.2004. tb08281.x

Cheney, D., Lynass, L., Flower, A., Waugh, M., Iwaszuk, W., Mielenz, C., \& Hawken, L. (2010). The check, connect, and expect program: A targeted, tier 2 intervention in the schoolwide positive behavior support model. Preventing School Failure, 54(3), 152-158 https://doi.org/10.1080/10459880903492742

Cho, H., Hallfors, D. D., \& Sanchez, V. (2005). Evaluation of a high school peer group intervention for at-risk youth. Journal of Abnormal Child Psychology, 33(3), 363-374. https://doi.org/10.1007/s10802-005-3574-4

Christle, C. A., Jolivette, K., \& Nelson, M. (2007). School characteristics related to high school dropout rates. Remedial and Special Education, 28(6), 325-339. https://doi.org/10.1177/ 07419325070280060201

Deci, E. L., \& Ryan, R. M. (2000). The "what" and "why" of goal pursuits: Human needs and the self-determination of behavior. Psychological Inquiry, 11, 227-268. https://doi.org/ 10.1207/s15327965pli1104_01

Dickens, L. R. (2017). Using gratitude to promote positive change: A series of meta-analyses investigating the effectiveness of gratitude interventions. Basic and Applied Social Psychology, 39(4), 193-208. https://doi.org/10.1080/01973533.2017.1323638

Flannery, K. B., Fenning, P., McGrath Kato, M., \& McIntosh, K. (2014). Effects of school-wide positive behavioral interventions and supports and fidelity of implementation on problem behavior in high schools. School Psychology Quarterly, 29(2), 111-124. https://doi.org/10.1037/spq0000039

Flannery, K. B., Frank, J. L., Kato, M. M, Doren, B., \& Fenning, P. (2013). Implementing schoolwide positive behavior support in high school settings: Analysis of eight high schools. High School Journal, 96(4), 267-282. https://doi.org/10.1353/hsj.2013.0015

Freeman, J., Simonsen, B., McCoach, B., Sugai, G., Lombardi, A., \& Horner, R. (2015). An analysis of the relationship between implementation of school-wide positive behavior interventions and supports and high school dropout rates. The High School Journal, 98(4), 290-315. https://doi.org/10.1353/hsj.2015.0009

Freeman, J., Simonsen, B., McCoach, B., Sugai, G., Lombardi, A., \& Horner, R. (2016). Relationship between school-wide positive behavior interventions and supports and academic, 
attendance, and behavior outcomes in high schools. Journal of Positive Behavior Interventions, 18(1), 41-51. https://doi.org/10.1177/1098300715580992

Hawken, L., Wayman, G., Wright, H. M., O’Donnell, K., Fleming, J., \& Rolfe, J. (2018). Effects of School of Life Foundation intervention on grade advancement, dropout and attendance: A descriptive study. Research Journal of Education, 4(12), 221-229.

Henry, K. L., Knight, K. E., \& Thornberry, T. P. (2012). School disengagement as a predictor of dropout, delinquency, and problem substance use during adolescence and early adulthood. Youth Adolescence, 41, 156-166. https://doi.org/10.1007/s10964-011-9665-3

Maynard, B. R., Kjellstrand, E. K., \& Thompson, A. M. (2014). Effects of check and connect on attendance, behavior, and academics: A randomized effectiveness trial. Research on Social Work Practice, 24(3), 296-309. https://doi.org/10.1177/1049731513497804

McDaniel, S. C., Houchins, D. E., \& Robinson, C. (2016). The effects of check, connect, and expect on behavioral and academic growth. Journal of Emotional and Behavioral Disorders, 24(1), 42-53. https://doi.org/10.1177/1063426615573262

McIntosh, K., Bennett, J. L., \& Price, K. (2011). Evaluation of social and academic effects of school-wide positive behavior support in a Canadian school district. Exceptionality Education International, 21(1), 46-60. https://doi.org/10.5206/eei.v21i1.7669

Morrissey, K. L., Bohanon, H., \& Fenning, P. (2010). Positive behavior support: Teaching and acknowledging expected behaviors in an urban high school. Teaching Exceptional Children, 42(5), 26-35. https://doi.org/10.1177/004005991004200503

Niehaus, K., Rudasill, K. M., \& Rakes, C. R. (2012). A longitudinal study of connectedness and academic outcomes across sixth grade. Journal of School Psychology, 50, 443-460. https://doi.org/10.1016/j.jsp.2012.03.002

Rolfe, J. (2014). School of Life (Student Edition): Learn to "School" Your Toughest Opponent (Unpublished manual).

Ross, S. W., \& Sabey, C. V. (2015). Check-in check-out + social skills: Enhancing the effects of check-in check-out for students with social skill deficits. Remedial and Special Education, 36(4), 246-257. https://doi.org/10.1177/0741932514553125

Sinclair, M. F., Christenson, S. L., Evelo, D. L., \& Hurley, C. M. (1998). Dropout prevention for high-risk youth with disabilities: Efficacy of a sustained school engagement procedure. Exceptional Children, 65, 7-21. https://doi.org/ 10.1177/001440299806500101

Swain-Bradway, J., Pinkney, C., \& Flannery, B. K. (2015). Implementing schoolwide positive behavior interventions and supports in high schools. Teaching Exceptional Children, 47(5), 245-255. https://doi.org/10.1177/0040059915580030

U.S. Department of Education. (2018). The Condition of Education 2018 (NCES 2018-144), Status Dropout Rates. National Center for Education Statistics, U.S. Department of Education.

Vallerand, R. J., Fortier, M. S., \& Guay, F. (1997). Self-determination and persistence in a 


\section{Macrothink}

real-life setting: Toward a motivational model of high school dropout. Journal of Personality and Social Psychology, 72, 1161-1176. https://doi.org/10.1037//0022-3514.72.5.1161

Vincent, C. G., \& Tobin, T. J. (2011). The relationship between implementation of school-wide positive behavior support (SWPBS) and disciplinary exclusion of students from various ethnic backgrounds with and without disabilities. Journal of Emotional and Behavioral Disorders, 19(4), 217-232. https://doi.org/10.1177/1063426610377329

Wehmeyer, M., \& Schwartz, M. (1997). Self-determination and positive adult outcomes: A follow-up study of youth with mental retardation or learning disabilities. Exceptional Children, 63(2), 245-256. https://doi.org/10.1177/001440299706300207

Zhang, D., \& Law, B. H. (2005). Self-Determination as a dropout prevention strategy. The Journal of At-Risk Issues, 11(2), 25-31.

\section{Copyright Disclaimer}

Copyright for this article is retained by the author(s), with first publication rights granted to the journal.

This is an open-access article distributed under the terms and conditions of the Creative Commons Attribution license (http://creativecommons.org/licenses/by/3.0/). 